\title{
ESTUDO DO APORTE TÉRMICO DE SOLDAGEM NO COMPORTAMENTO BALÍSTICO DE UM AÇO DE ALTA DUREZA (HHA - HIGH HARDNESS ARMOR)*
}

\author{
Elson Renato Santos Souza ${ }^{1}$ \\ Ricardo Pondé Weber ${ }^{2}$ \\ João Carlos Miguez Suarez ${ }^{3}$ \\ Sergio Neves Monteiro ${ }^{4}$ \\ Suzane de Sant' Ana Oliveira ${ }^{5}$
}

\section{Resumo}

Foi estudado a influência do aporte térmico, de soldagem, sobre a resistência balística de um aço de alta dureza (HHA) temperado e revenido (HHA), utilizando o processo de soldagem a arco. $\mathrm{O}$ aço HHA, temperado e revenido, foi caracterizado por análise metalográfica, ensaios mecânicos e ensaios balísticos. Os resultados mostram que 0 aporte térmico da soldagem teve influência significativa nas propriedades mecânicas da Zona de Fusão (ZF) e da Zona Termicamante Afetada (ZTA), ocasionando mudanças na resistência balística. O melhor desempenho balístico do material soldado foi obtido para a soldagem de baixo aporte térmico.

Palavras-chave:Blindagem de aço; Soldagem a arco elétrico com eletrodo revestido (SMAW); Zona de fusão (ZF); Zona termicamente afetada (ZTA).

\section{EFFECT OF WELDING HEAT ON THE BALLISTIC RESISTANCE OF A HIGH HARDNESS AMOR (HHA) STEEL}

\section{Abstract}

A study was carried out to evaluate the influence of the amount of welding heat on the ballistic resistance of a Brazilian quenched and tempered (Q\&T) high hardness armor (HHA) steel welded by an arc-welding method. The Q\&T HHA steel was characterized by metallographic examination, mechanical tests and ballistic tests. The results showed that the amount of welding heat had a significant influence on the mechanical properties of the fusion zone (FZ) and the heat-affected zone (HAZ), leading to changes in the ballistic resistance. The best ballistic performance was observed for the least heat input.

Keywords: Armor steel; Shielded metal arc welding (SMAW); Fusion zone (FZ); Heat affected zone (HAZ).

1 Engenharia de Materiais, Mestre, Engenheiro de Pesquisa e Desenvolvimento de Blindagens, Departamento de Ciência e Tecnologia, Exército Brasileiro, Rio de Janeiro, RJ, Brasil.

2 Engenharia Mecânica, Doutor, Professor do curso de Ciência dos Materiais, Seção de Engenharia Mecânica e de Materiais, Instituto Militar de Engenharia, Rio de Janeiro, RJ, Brasil.

3 Engenharia Industrial e de Metalurgia, Doutor em Ciência e Tecnologia dos Polímeros, Seção de Engenharia Mecânica e de Materiais, Instituto Militar de Engenharia, Rio de Janeiro, RJ, Brasil.

4 Engenheiro Metalurgista, Ph.D, Professor titular, Seção de Engenharia Mecânica e de Materiais, Instituto Militar de Engenharia, Rio de Janeiro, RJ, Brasil.

5 Tecnologia em Processos Metalúrgicos, Mestre, Doutoranda em Ciência dos Materiais, Seção de Engenharia Mecânica e de Materiais, Instituto Militar de Engenharia, Rio de Janeiro, RJ, Brasil. 


\section{INTRODUÇÃO}

Os aços utilizados como blindagem balística requerem alta dureza, para evitarem a penetração nas blindagens, bem como uma boa tenacidade, para evitar 0 estilhaçamento do mesmo, após o impacto [1]. O meio para alcançar ambas as propriedades, além de um tratamento térmico, é adicionar elementos de liga que aumentam a capacidade de endurecimento do material [2]. No caso dos aços de alta dureza (HHA), os principais aditivos químicos são cromo, níquel e molibdênio. No entanto, 0 aporte térmico durante a soldagem pode alterar significativamente as propriedades mecânicas do material, possivelmente comprometendo a proteção balística [3-6].

As propriedades de um aço HHA foram estudadas para dois tipos de aportes térmicos de soldagem, utilizando o processo de soldagem a arco elétrico com eletrodo revestido (SMAW). Ensaios mecânicos (de impacto Charpy e dureza) foram realizados nessas duas condições. Ensaios balísticos foram realizados na ZF e na ZTA, medindo a energia de impacto, bem como o limite balístico $\left(\mathrm{V}_{50}\right)$ e o modo de perfuração - Perfuração parcial (PP) ou Perfuração Completa (PC). Os resultados para os dois aportes de calor foram comparados para avaliar a influência do aporte térmico da soldagem no desempenho balístico.

\section{MATERIAIS E MÉTODOS}

O material utilizado neste trabalho foi o aço de alta dureza (HHA) desenvolvido e fabricado de acordo com a norma MIL-DTL-46100E por uma empresa brasileira. Foi fornecido emplacas laminadas de $8 \mathrm{~mm}$ de espessura. $O$ tratamento térmico (tempera e revenido) produziu uma dureza de $480 \mathrm{HB}$.

A composição química deste material é mostrada na Tabela 1.

Tabela 1. Composição química do aço HHA.

\begin{tabular}{|c|c|c|c|c|c|c|c|c|c|}
\hline Elemento & $\mathrm{C}$ & $\mathrm{Mn}$ & $\mathrm{Si}$ & $\mathrm{Ni}$ & $\mathrm{Cr}$ & $\mathrm{Mo}$ & $\mathrm{Cu}$ & $\mathrm{Ti}$ & $\mathbf{P}+\mathbf{S}$ \\
\hline$\%$ & $\mathbf{0 . 3 1}$ & $\mathbf{0 . 4 2}$ & $\mathbf{0 . 9 3}$ & $\mathbf{0 . 5 7}$ & $\mathbf{0 . 7 6}$ & $\mathbf{0 . 3 0}$ & $\mathbf{0 . 0 5}$ & $\mathbf{0 . 0 3}$ & $\mathbf{0 . 0 0 9}$ \\
\hline
\end{tabular}

O limite balístico ou $V_{50}$ do material base, que é a velocidade a qual a probabilidade de perfuração é de 50\%, medida de acordo coma norma MIL-DTL-46100E [7] e MILSTD-662F [8], é de $585 \mathrm{~m} / \mathrm{s}$.

O metal de adição utilizado para produzir as amostras soldadas foi o eletrodo ferrítico de baixo teor de hidrogênio classificado como AWS 7018-1 [9].

O processo de soldagem utilizado foi o SMAW em chapas chanfradas de 500×250 $\mathrm{mm}$ como mostrado esquematicamente na Figura 1

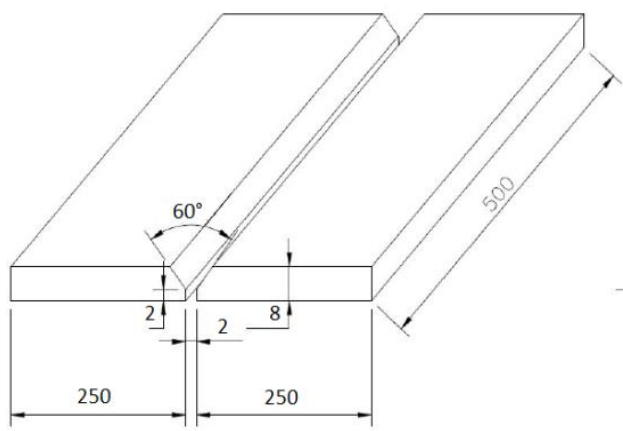

Figura 1. Amostra soldada. 
Foram investigados dois aportes térmicos diferentes: um considerado como alto aporte térmico e outro como baixo aporte térmico. Os diferentes aportes térmicos foram obtidos usando eletrodos com parâmetros de soldagem distintos, como mostrado na Tabela 2.

Tabela2. Parâmetros da soldagem.

\begin{tabular}{|c|c|c|c|c|}
\hline $\begin{array}{c}\text { Diâmetro do } \\
\text { eletrodo }(\mathbf{m m})\end{array}$ & $\begin{array}{c}\text { Corrente } \\
\text { elétrica } \\
(\mathbf{I})\end{array}$ & $\begin{array}{c}\text { Voltagem } \\
\text { medida } \\
\text { (V) }\end{array}$ & $\begin{array}{c}\text { Velocidade de } \\
\text { soldagem } \\
\text { (cm/min) }\end{array}$ & $\begin{array}{c}\text { Aporte } \\
\text { térmico } \\
\text { (kJ/cm) }\end{array}$ \\
\hline 2.5 & 68.1 & 21 & 10.6 & 8.1 (Baixo) \\
\hline 3.25 & 84.7 & 21 & 8.91 & 11.98 (Alto) \\
\hline
\end{tabular}

O perfil de dureza por microindentação Vickers do cordão de solda nas condições de alto e baixo aporte está esquematicamente representado na Figura 2.

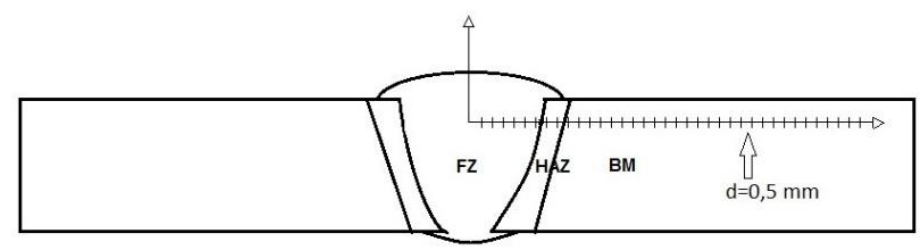

Figura 2. Perfil de dureza por microindentaçãoVickers.

\section{RESULTADOS E DISCUSSÃo}

\subsection{Ensaio de impacto Charpy}

As energias médias do ensaio de impacto são apresentadas na Tabela 3. 0 cordão de solda apresenta uma maior absorção de energia do que o MB, indicando que 0 cordão de solda possui uma dureza maior que o MB. No entanto, pode-se ver que o alto aporte térmico resulta em maior resistência no cordão de solda, provavelmente devido à ampla região amolecida da ZTA [11], aumentando a absorção de energia no impacto.

Tabela3. Valores de energia absorvida no ensaio de impacto Charpy a temperatura ambiente.

\begin{tabular}{|c|c|c|c|}
\hline Propriedade & \multicolumn{3}{|c|}{ Amostra } \\
\hline & MB & Alto aporte térmico & Baixo aporte térmico \\
\hline Energia de Impacto (J) & 29 & 68,75 & 53,25 \\
\hline
\end{tabular}

\subsection{Perfil de dureza por microindetaçãoVickers}

O perfil de dureza ao longo da junção entre o cordão de solda e o metal base, em ambas as condições de soldagem, está apresentado na Figura 3.

Pode-se ver em ambas as condições de soldagem quatro (4) regiões diferentes: 
- 1a região: região de baixa dureza consistindo da zona de fusão (ZF), onde o metal de adição é predominante e tem uma microestrutura dúctil de ferrita acicular;

- $2^{\underline{a}}$ região: localizada perto da interface ZF / ZTA com alta dureza como resultado da martensita grosseira e fina;

- 3a região: conhecida como ZTP localizada no final da ZTA, mostrando uma diminuição acentuada da dureza devido à presença da martensita, ferrita e bainita;

- 4a região: um aumento contínuo da dureza devido às temperaturas mais baixas atingidas nesta região. Ela apresenta a mesma microestrutura que a $3^{\underline{a}}$ região, mas com menor porcentagem de bainita e ferrita.

Estes resultados estão de acordo com o comportamento mecânico do cordão de solda. A soldagem de alto aporte térmico tem a menor dureza, bem como a maior absorção de energia e a menor resistência à tração no cordão de solda.

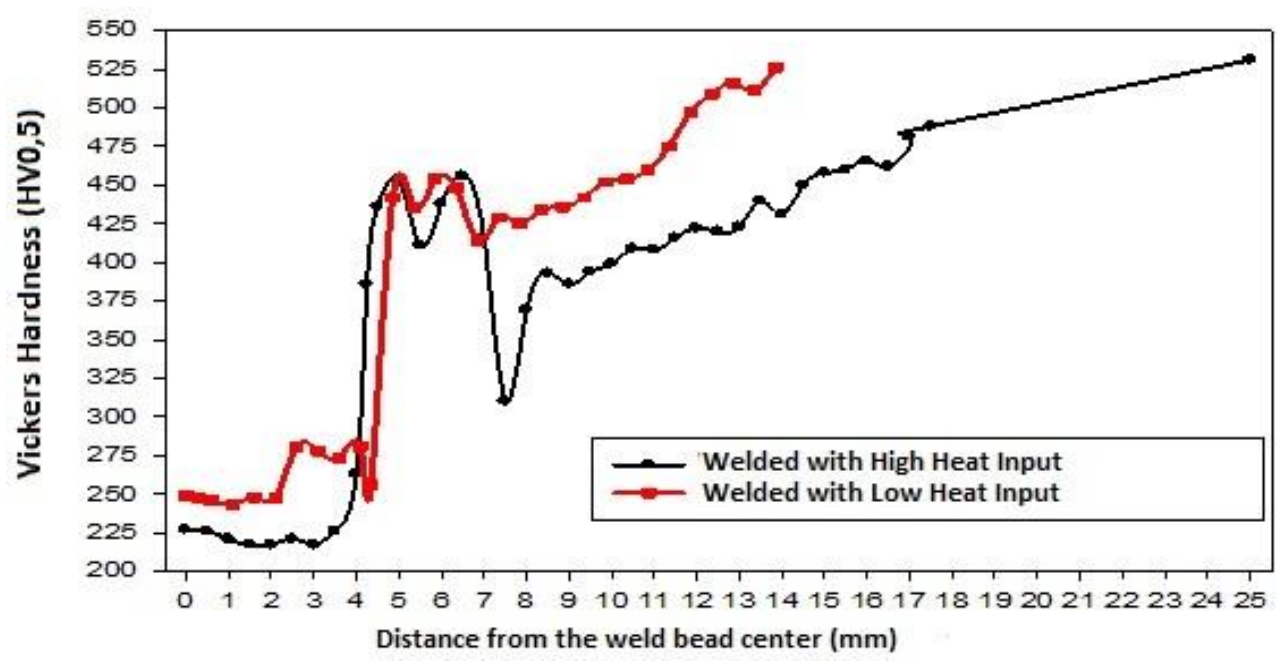

Figura 3. Perfil de dureza do cordão de solda.

\subsection{Ensaio balístico}

A Figura 4 apresenta as amostras após o ensaio balístico.

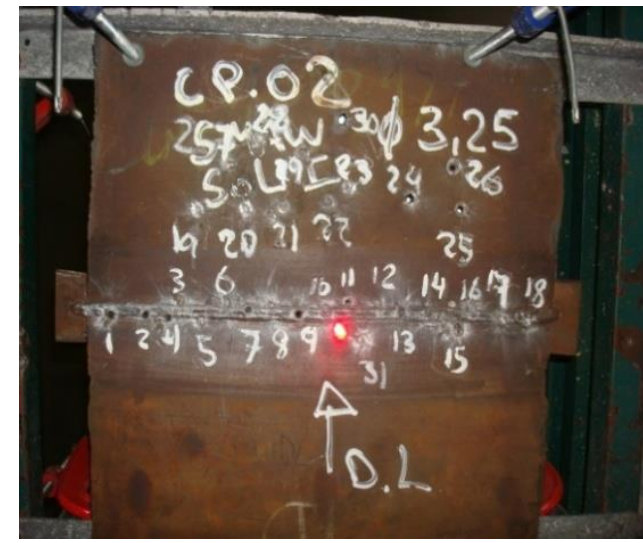

(a)

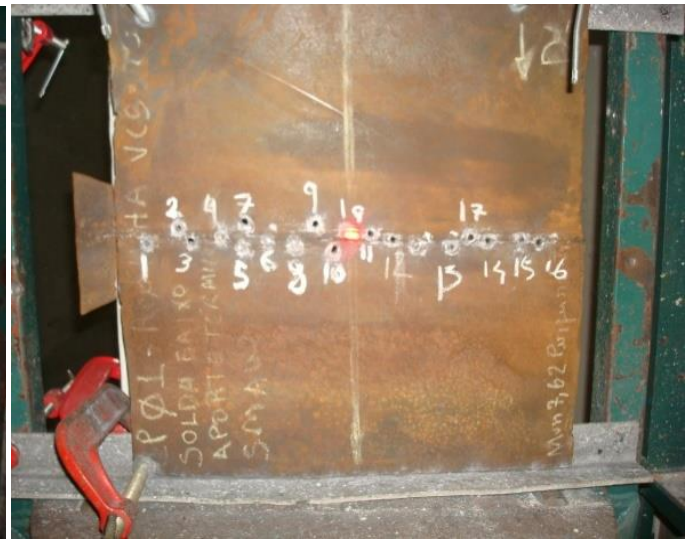

(b)

Figura 5. Ensaio balístico nas amostras soldadas (a) com alto aporte térmico e (b) com baixo aporte térmico. 
A Tabela 4 mostra os resultados do ensaio balístico para ambas as condições, com alto aporte térmico e baixo aporte térmico.

Tabela 4. Resultado balístico das amostras soldadas.

\begin{tabular}{|c|c|c|c|c|c|}
\hline \multirow{2}{*}{$\begin{array}{l}\text { Aporte } \\
\text { Térmico }\end{array}$} & \multicolumn{2}{|c|}{ Impacto } & \multirow{2}{*}{$\begin{array}{l}\text { Velocidade de } \\
\text { impacto }(\mathrm{m} / \mathrm{s})\end{array}$} & \multirow{2}{*}{$\begin{array}{l}\text { Energia de } \\
\text { impacto }(\mathrm{J})\end{array}$} & \multirow[t]{2}{*}{ Resultado } \\
\hline & № & Região & & & \\
\hline \multirow{10}{*}{ Alto aporte } & 1 & \multirow{4}{*}{$\mathbf{Z F}$} & 552 & 1462 & PC \\
\hline & 2 & & 529 & 1343 & PP \\
\hline & 3 & & 494 & 1171 & PP \\
\hline & 4 & & 551 & 1457 & PC \\
\hline & & & $V 50=532$ & $E V 50=1359$ & \\
\hline & 1 & \multirow{4}{*}{ ZTA } & 607 & 1768 & PP \\
\hline & 2 & & 616 & 1821 & PC \\
\hline & 3 & & 597 & 1710 & PP \\
\hline & 4 & & 670 & 2154 & PC \\
\hline & & & $V 50=622$ & $E V 50=1359$ & \\
\hline \multirow{10}{*}{ Baixo aporte } & 1 & \multirow{4}{*}{ ZF } & 627 & 1887 & PP \\
\hline & 2 & & 543 & 1415 & PC \\
\hline & 3 & & 500 & 1200 & PP \\
\hline & 4 & & 556 & 1484 & PC \\
\hline & & & $V_{50}=556$ & $E_{v 50}=1496$ & \\
\hline & 1 & \multirow{4}{*}{ ZAT } & 682 & 2232 & PC \\
\hline & 2 & & 663 & 2110 & PP \\
\hline & 3 & & 665 & 2129 & PC \\
\hline & 4 & & 661 & 2097 & PP \\
\hline & & & $V_{50}=668$ & $E_{v 50}=2142$ & \\
\hline
\end{tabular}

Pode notar-se que, em ambas as condições, alto e baixo aporte térmico, o limite balístico $\mathrm{V}_{50}$ da zona de fusão $(\mathrm{ZF})$ é inferior ao do metal base $(585 \mathrm{~m} / \mathrm{s})$. Por outro lado, o limite balístico $V_{50}$ da ZTA é maior que o do metal base em ambas as condições. Isso indica que, independentemente do aporte térmico, a ZTA mantém uma resistência balística maior que a do metal base.

A resistência balística para a soldagem de baixo aporte térmico é maior do que a soldagem de alto aporte térmico, independentemente da região considerada (ZF ou ZTA). Esses resultados estão de acordo com os ensaios de tração, impacto e dureza.

A pior resposta do comportamento balístico na ZF em relação à ZTA está relacionada à microestrutura da ferrita acicular, que produz menor dureza e menor resistência à penetração em comparação com a microestrutura martensítica da ZTA. A melhor resistência balística na ZF da soldagem de baixo aporte térmico, quando comparada com a soldagem de alto aporte térmico, está relacionada ao tamanho de grão menor na microestrutura de ferrita acicular.

\section{CONCLUSÃo}

- A absorção de energia após o ensaio de impacto foi modificada pelo alto aporte. Quanto maior a entrada de calor, maior a absorção de energia. 
- O perfil de dureza em ambas as condições de aporte térmico mostrou uma ZTA mais estreita para o baixo aporte e uma menor dureza da ZF para o alto aporte.

- O ensaio balístico revelou que o limite balístico $V_{50}$ nas regiões ZF e ZTA é maior para a amostra de baixa aporte térmico, sugerindo que esta condição produz o melhor desempenho balístico.

\section{Agradecimentos}

Os autores agradecem ao Exército brasileiro e às agências financeiras nacionais (CNPq, CAPES e FAPERJ) por patrocinar esta pesquisa.

\section{REFERÊNCIAS}

1 Jena P, Mishra B, Rameshbabu M, Babu A, Singh AK, Sivakumar K, Bhat, T B. Effect of Heat Treatment on Mechanical and Ballistic Properties of a High Strength Armor Steel. International Journal of Impact Engineering. 2010; 37:242-249.

2 Costa e Silva, ALV da; Mei, PR. Aços e Ligas Especiais. 2. ed. São Paulo, ed Edgard Blucher, 2006

3 Balakrishnan M, Balasubramanian V, Madhusuhan G R, Sivakumar K, Effect of Buttering and Hardfacing on Ballistic Performance of Shielded Metal Arc Welded Armour Steel Joints, Materials and Design. 2011; 32(1): 469-479.

4 Madhusudhan GR, Mohandas T. Ballistic Performance of High-strength Low-Alloy Steel Weldments, Journal of Materials Processing Technology. 1996; 57(1): 23-30.

5 Madhusudhan GR, Mohandas T, Papukutty KK. Effect of Welding Process on the Ballistic Performance of High-Strength Low-Alloy Steel Weldments, Journal of Materials Processing Technology. 1996; 74(1): 27-35.

6 Edwards MR. e A Mathewson. The Ballistic Properties of Tool Steel as a Potential Improvised Armour Plate. Journal of Impact Engineering, Shirivinham, Condado de Swindon. 1997;19(4): 297309.

7 U S Army. MIL-DTL-46100E (MR), Amendment 1, Detail Specification Armor Plate, Steel, Wrought, High-Hardness, 2008

8 U.S. Department of Army. Standard MIL-STD-662F - V50 Ballistic Test for Armor, 1997

9 Weber, RP, Chawla, KK, B, Miguez, JC Suarez, Influence of notch orientation and temperature on the impact behavior of a dual hardness steel composite. Materials Science \& Engineering, A. 2013; 580: 279-287. 